hypersensitivity, and chronic fatigue syndrome. International Journal of Mental Health, 19, 56-68.

WelsBy, P. (1990) Counselling and care of chronic fatigue syndrome. Pulse, November 10th, 79-80.

ELLEN M. Goudsmit

International Federation of $M E$ Associations

23 Melbourne Road

Teddington

Middlesex TW11 9QX

ME Association

C. SHEPHERD

\section{DASH scale}

SIR: Expansion or clarification of the DSM-III-R categories, which illuminates and improves the quality of life of persons with learning disability, is to be welcomed. Despite the rigorous data collection carried out by Matson et al (Journal, September $1991,159,404-409)$ the DASH scale deserves critical attention.

The authors have restricted their attention to DSM-III-R's Axes I and II. They have ignored Axis III (medical conditions), Axis IV (environmental conditions likely to trigger Axis I and II conditions), and Axis $V$ (the person's functional strengths). DSM-III-R's strength is that it includes categories essential in a useful description of the person and the context in which Axis I and II conditions are manifest. These focus on the likely interventions and, therefore, resources needed to improve the individuals' performance and quality of life. Failure to record Axes IV and $\mathbf{V}$ creates serious problems in applying the categories to an individual, since it appears to suggest that a person's behaviour is independent of environmental factors, and fails to take account of the possible functions of the behaviour. Many people with and without learning disabilities show a clear escalation cycle of behaviour which is related to the response style of the people with whom they are interacting.

The following examples are taken from people with learning disabilities.

(a) A person asks appropriately for a cup of tea, and receives the answer 'no' or is ignored. After repeating the request appropriately several times she attempts to take cups of tea being held by others. Appropriate requests for more food are refused or ignored in the same way, and are followed by attempts to take others' food. As this is effectively blocked, the person starts vomiting on a table top or floor, and eating it up before staff can wipe or vacuum it away. Given ordinary food when she requests it appropriately, the person prefers this and stops the self-induced vomiting. As long as her appropriate requests are ignored (a clear Axis IV problem) this person will score items $1,3,4$ of eating disorders, and items 1,11 , and 13 of impulse control and miscellaneous behaviour problems. If she hits out or expresses displeasure verbally at staff or other people, she is also likely to score on items 2 and 5 of this category.

(b) A person who sits rocking in a chair is called to come and eat. She shouts 'no' clearly and gesticulates annoyance to the adult approaching her. The adult continues forward to the person, puts out her hand to the person and repeats her request several times, each time meeting a louder shout of 'no' and clearer gestures confirming the verbal communication. The adult takes the person by the hand and prompts her to stand up and come to the dinner table. The person lifts up her arm and punches the adult on the face and chases her out of the room. Four adults move towards the person to restrain her, and the adult nearest the person's head is bitten on the hand. When adults invite the person to join in activities while standing still, from a distance of four feet or more, and when they respond early to the person's 'no' to invitations to dinner, and repeat the invitation some time later, the escalations in assault behaviour almost cease, and the person participates in a wider range of interesting activities. Under the above Axis IV conditions this person scores item 5 of rating disorders, and items $1,2,3,4$, and 5 of impulse control and miscellaneous behaviour problems.

(c) A person can express sexuality appropriately and discretely in a long-term relationship where this is supported by adults in authority. With policy changes, a veto is placed both on meetings between the friends, and particularly on their expressions of mutual sexuality. They then meet secretly but indiscretely around the campus where their masturbation is more observable by passers by. One of the partners also approaches other people and makes indiscrete sexual propositions to them, and the people approached complain. Under these Axis IV conditions these people score items 1,2, and possibly 3 of sexual disorders.

Attention to all axes of DSM-III-R may, if done accurately, illuminate these complex situations, and create opportunities for caring adults of all disciplines to collaborate in finding creative ways of overcoming what appear to be impossible problems through simple but important improvements in the environment of the people for whom they have responsibility.

Descriptions restricted to Axes I and II may both prolong the practice of blaming or labelling victims, and get in the way of effective and humane 
clinical practices which can be easily monitored and evaluated.

\section{Graham Unit \\ Lymington Day Hospitals \\ Hampshire SO4 9ZJ}

\section{Delusional memory in schizophrenia}

SIR: Buchanan (Journal, October 1991, 159, 472-474) grapples manfully with the literature on delusional memory in schizophrenia but concludes that the overall significance of the phenomenon has yet to be clarified. To a large extent, the woeful lack of consensus between authors, highlighted by Dr Buchanan, as to what exactly constitutes delusional memory, is responsible for continued uncertainty about its diagnostic usefulness. As psychiatrists we have a tendency, when approaching phenomenological murky waters, to fall back on comparisons of our patients' experiences with those of the great early descriptive writers. In some ways this is constructive and may allow us to recognise and appreciate the significance of particular signs and symptoms, but where authoritative opinions on a particular phenomenon have not coincided, we are left in an uncomfortable situation. Such is the case with delusional memory. Before we can progress further in our exploration of this symptom and its diagnostic significance, we should perhaps stop thinking in antique terms, and start again from the simplest level by describing delusional memory experiences in terms of their basic components.

From the descriptions of what has been termed 'delusional memory' reviewed by Buchanan, we would suggest that three types of delusional memory are recognised by the following easy-to-understand steps in memory falsification.

Type 1. Simple memory falsification delusional memory. This corresponds to the PSE definition of 'experiences of past events which clearly did not occur but which the subject equally clearly remembers' (Wing et al, 1974). No delusional interpretation has been involved in the production of these memories, they are purely memories that have been fabricated

Type 2 . True memory with delusionally attributed significance delusional memory. This has the twomemberedness of a delusional perception and is illustrated by the example of Kurt Schneider's patient who recalled that his fork when he was a child had a crown on it and that this signified he was of noble birth (Schneider, 1949).

Type 3. False memory with delusionally attributed significance delusional memory. This would be as for
Type 2, except that, in the example given, the child's fork if still available would be found not to have had a crown on it. The distinction between Type 2 and Type 3 is generally based on the 'believability' of the events in the memory involved and not upon a hunt for an item of childhood cutlery!

Memory falsifications are not found exclusively in schizophrenia. Patients may confabulate to cover an amnestic disorder or just be telling lies. Nostalgia in healthy individuals involves a degree of memory falsification. Reduplicative paramnesia, like delusional memory, has come to mean many things, but as originally described was specifically a falsification of memory (Pick, 1903) and may indeed be confused with examples of delusional memory.

PICK, A. (1903) Clinical studies III. On reduplicative paramnesia. Brain, 26, 260-267.

Schneider, K. (1949) The concept of delusion. In Themes and Variations in European Psychiatry (eds S. Hirsch \& M. Shepherd). Bristol: Wright.

Wing, J. K., CoOper, J. E. \& Sartorius, N. (1974) The Measurement and Classification of Psychiatric Symptoms. London: Cambridge University Press.

ROBERT HOWARD

Institute of Psychiatry

Alistair Burns

De Crespigny Park

London SE5 8AF

\section{Biological basis of behaviour}

SIR: Publicity in the media has recently been given to an article by Le Vay (1991) in which he showed that the size of a group of cells in the interstitial nuclei of the hypothalamus (INAH 3) was twice as large in heterosexual men as in homosexual men. The smaller size is similar to that found in women.

In 1986 , Primrose showed that while only $15 \%$ $(21 / 138)$ of adult males in a hospital for mental handicap had a lower than normal serum testosterone level, $73 \%$ of them $(102 / 139)$ had an immature level of serum follicle stimulating hormone which is a hypothalamic-mediated pituitary hormone. In general, sexual expression in male mental handicap remains at an immature level, although testicular volume is usually of normal size. (In the series quoted, $20 \%$ or $74 / 377$ had testes below normal size).

If such sexual behaviour patterns are biologically determined - and possibly from an early age - then this raises not only moral and legal issues for society, but also indicates the limits which can be expected from treatment of an individual, should this be considered necessary.

LE VAY, S. (1991) A difference in hypothalamic structure between heterosexual and homosexual men. Science, 253, 1034-1037. 